\title{
Effect of coronavirus disease 2019 pandemic on the lifestyle and glycemic control in patients with type 2 diabetes: a cross-section and retrospective cohort study
}

\author{
Chihiro Munekawa *, Yukako Hosomi *, Yoshitaka Hashimoto, Takuro Okamura, Fuyuko Takahashi, \\ Rena Kawano, Hanako Nakajima, Takafumi Osaka, Hiroshi Okada, Saori Majima, Takafumi Senmaru, \\ Naoko Nakanishi, Emi Ushigome, Masahide Hamaguchi, Masahiro Yamazaki and Michiaki Fukui
}

\begin{abstract}
Department of Endocrinology and Metabolism, Kyoto Prefectural University of Medicine, Graduate School of Medical Science, Kyoto 602-8566, Japan
\end{abstract}

\begin{abstract}
To investigate the acute effects of the coronavirus disease 2019 (COVID-19) on the lifestyle and metabolic parameters in patients with type 2 diabetes mellites. This cross-sectional and retrospective cohort study induced 203 patients who completed a questionnaire regarding stress levels and lifestyles. Data regarding stress levels, sleep time, exercise, and total diet, snack, and prepared food intake were obtained from the questionnaires. The changes in the body weight or HbA1c levels were determined by comparing the values at the time the questionnaire was administered to those noted 3 months ago. Increased levels of stress and decreased exercise levels were reported in approximately $40 \%$ and $>50 \%$. During the COVID-19 pandemic. There was a negative correlation between stress and exercise $(r=-0.285, p<0.001)$ and a positive correlation between stress and prepared food intake $(r=0.193, p=0.009)$. Decreased exercise levels $(r=-0.33, p<0.001)$ and increased snack consumption $(r=0.24, p=0.002)$ were associated with increased body weight. Furthermore, increased total diet intake $(r=0.16, p=0.031)$ was associated with increased HbAlc levels. These relationships remained significant for patients aged $<65$ years and patients who did not engage in regular exercise. Many patients experienced stress and lifestyle changes due to the COVID-19 pandemic, and these changes were associated with increased body weight and HbAlc levels.
\end{abstract}

Key words: COVID-19, Pandemic, Type 2 diabetes, Stress, Exercise

CORONAVIRUSES (CoV) are envelop-type viruses with a single-stranded, positive-sense ribonucleic acid genome that is known to cause respiratory infections in humans [1]. Although most human $\mathrm{CoV}$ infections are not severe, two major outbreaks of $\mathrm{CoV}$ infection have occurred in the past, namely severe acute respiratory syndrome coronavirus (SARS-CoV) infection in 20022003 and Middle East respiratory syndrome coronavirus (MERS-CoV) infection in 2012 [2-4]. A new coronavirus, SARS-CoV-2, was distinguished as the pathogen causing coronavirus disease COVID-19 in Wuhan, China in December 2019 [5]. On March 11, 2020, the World Health Organization declared COVID-19 a pandemic

Submitted Jul. 6, 2020; Accepted Sep. 2, 2020 as EJ20-0426

Released online in J-STAGE as advance publication Sep. 29, 2020

Correspondence to: Yoshitaka Hashimoto, MD, PhD, Department of Endocrinology and Metabolism, Graduate School of Medical Science, Kyoto Prefectural University of Medicine, 465 Kajii-cho, Kawaramachi-Hirokoji, Kamigyo-ku, Kyoto 602-8566, Japan. E-mail: y-hashi@koto.kpu-m.ac.jp

*These authors equally contributed to this work.
[6]. By May 1, 2020, 233,560 deaths were reported among 3,269,667 confirmed cases worldwide and 430 deaths have been reported among 14,088 confirmed cases in Japan [7].

To block the spread of COVID-19, European countries have significantly curbed public life. In Japan, a state of emergency, with request-based measures of encouraging the populace to remain at home and businesses to limit operations, was declared on April 7, 2020. Therefore, the Japanese are also becoming more restrictive in their behavior. On the other hand, infectious disease outbreaks, including COVID-19, are associated with increased stress [8, 9]. Moreover, previous studies showed that disasters were associated with increased stress and worse glycemic control in patients with type 2 diabetes mellitus [10].

Patients with diabetes mellitus are more likely to develop COVID-19 and are at a higher risk of mortality [11-13]. Although patients with diabetes mellitus should be careful to avoid COVID-19 infection, there is a possibility that forcing these patients to restrict their life may 
worsen their glucose control. However, the effect of the COVID-19 pandemic on the mental health and lifestyle of patients with type 2 diabetes mellitus is currently unknown. Therefore, in this cross-sectional study, we aimed to investigate the acute effects of the COVID-19 pandemic on the lifestyle changes in patients with type 2 diabetes mellitus. Furthermore, we also investigated the association between these changes and metabolic parameters, including body weight and hemoglobin Alc (HbA1c) levels, by conducting a retrospective cohort study.

\section{Materials and Methods}

\section{Study patients}

To clarify the natural history of the patients with diabetes mellitus, we are performing an ongoing opt-out survey among the patients with diabetes mellitus. This study was approved by the ethics committee of Kyoto Prefectural University of Medicine (ERB-C-1291). In this cross-sectional study, a questionnaire was administered to the patients with type 2 diabetes mellitus who visited a clinic at the Department of Endocrinology and Metabolism, Kyoto Prefectural University of Medicine from April 16 to May 1, 2020. We excluded patients if they were admitted to the hospital during the past 3 months or provided incomplete answers to the questionnaires from the cross-sectional study and excluded those who changed their medication for diabetes during the past 3 months from the retrospective cohort study.

\section{Data collection and measurements}

Type 2 diabetes mellitus was diagnosed by the Report of the Expert Committee on the Diagnosis and Classification of Diabetes Mellitus [14]. According to the selfadministered questionnaire, the patients were classified as a non-, past-, or current smoker and patients who regularly played any type of sport for more than once per week, before COVID-19 pandemic, were defined as regular exercisers. Nephropathy was defined according to the report of the Joint Committee on Diabetic Nephropathy [15]. Neuropathy was defined by the diagnostic criteria for diabetic neuropathy suggested by the Diagnostic Neuropathy Study Group [16]. Retinopathy was classified, as follows: no diabetic-retinopathy (NDR), simple diabetic-retinopathy (SDR), and proliferative diabetic retinopathy (PDR), which included pre-proliferative retinopathy [17]. Data regarding the body weight and HbAlc levels at the time the questionnaire was administered and the values noted 3 months ago were obtained from medical records, and the difference between the values corresponding to these two time-points was calculated as the change in the body weight or $\mathrm{HbA} 1 \mathrm{c}$ levels.
Based on the patient's change in the body weight or HbA1c levels, we further classified them as weight gain or not, or worse glycemic control or not.

\section{Questionnaire}

Since the decreased contact time is essential to reduce the risk of disease transmission, we only asked the patients simple and a minimal number of questions. This questionnaire was performed by physician during medical examination. The questionnaire consisted of 6 short questions regarding stress and lifestyle factors. A visual analog scale (VAS; $0=$ considerably reduced, $5=$ no change, and $10=$ considerably increased) was used for all questions and patients were asked to score how their stress levels, sleep time, exercise levels, and total diet, snack, and prepared food intakes have changed due to the COVID-19 pandemic (Supplemental Table 1). Based on the patient's VAS scores, we further classified them as meeting or not meeting the following categories: increased stress (VAS $\geq 6$ ), shortened sleep time (VAS $\leq 4$ ), decreased exercise (VAS $\leq 4$ ), increased total diet intake (VAS $\geq 6$ ), increased snack consumption (VAS $\geq 6$ ), and increased prepared food intake (VAS $\geq 6$ ).

\section{Statistical analysis}

The statistical analyses were performed using the JMP version 13.1 software (SAS Institute Inc., Cary, NC) and $p$-values $<0.05$ were considered statistically significant. The mean or frequency of potential confounding variables was calculated. The continuous and categorical variables were presented as the means ( \pm standard deviations) and absolute numbers, respectively.

Spearman rank correlation was used to investigate the relationship among the changes in stress and lifestyle factors. Spearman rank correlation was also used to investigate the relationship between these changes in stress and lifestyle factors and changes in body weight or HbA1c levels. The differences in the change in body weight or HbAlc levels between the groups were evaluated using Mann-Whitney $U$ test. Furthermore, the differences in the lifestyle factors between the groups were evaluated using Mann-Whitney $U$ test. Subgroup analyses were performed to assess the relationship between the change in stress and lifestyle factors and change in metabolic parameters (i.e., body weight and $\mathrm{HbA} 1 \mathrm{c} \mathrm{lev-}$ els) according to sex, age ( $\geq 65$ years or $<65$ years) and exercise habit.

\section{Results}

In this study, among 564 patients who were scheduled to visit our department, 87 patients received telemedicine and 127 patients did not visit. Among 350 patients who 
Table 1 Clinical characteristics of the study participants

\begin{tabular}{lc}
\hline$n$ & 203 \\
\hline Age (year) & $67.4(11.3)$ \\
\hline Sex (men/women) & $126 / 77$ \\
\hline Duration of diabetes (year) & $14.4(10.1)$ \\
\hline Smoking (non-/past-/current smoker) & $99 / 81 / 23$ \\
\hline Exercise habit (no/yes) & $133 / 70$ \\
\hline Habitual alcohol intake (no/yes) & $120 / 83$ \\
\hline Nephropathy stage (1/2/3/4/5) & $120 / 54 / 15 / 11 / 3$ \\
\hline Neuropathy (no/yes) & $161 / 42$ \\
\hline Retinopathy (NDR/SDR/PDR) & $154 / 20 / 29$ \\
\hline Insulin usage (no/yes) & $135 / 68$ \\
Oral medication for diabetes (no/yes) & $33 / 170$ \\
\hline Questionnaires & \\
\hline Feel stress & $6.0(1.7)$ \\
\hline Increasing of stress (no/yes) & $118 / 85$ \\
\hline Sleep time & $4.9(1.4)$ \\
\hline Shorten sleep time (no/yes) & $164 / 39$ \\
\hline Exercise & $3.7(2.0)$ \\
\hline Decreasing of exercise (no/yes) & $93 / 109$ \\
\hline Total diet intake & $5.2(1.2)$ \\
\hline Increasing of total diet intake (no/yes) & $163 / 40$ \\
\hline Snack consumption & $4.9(1.6)$ \\
\hline Increasing of snack consumption (no/yes) & $166 / 37$ \\
\hline Prepared food intake & $5.1(1.3)$ \\
\hline Increasing of prepared food intake (no/yes) & $173 / 30$ \\
\hline & \\
\hline
\end{tabular}

NDR, non-diabetic retinopathy; SDR, simple diabetic retinopathy; PDR, proliferative diabetic retinopathy. All items of the change of stress and lifestyles factors were evaluated by used visual analog scale. $0=$ considerably reduced, $5=$ no change, $10=$ considerably increased.

visited our department, one patient rejected data usage, 121 patients did not have type 2 diabetes mellitus, 4 patients were admitted to the hospital during the past 3 months, and 22 patients had incomplete answers in the questionnaire. Therefore, 203 patients were eligible for this cross-sectional study (Fig. 1). We further excluded 20 patients because of changes to their medications during the past 3 months, and a total of 183 participants were included in the retrospective study. None of them infected COVID-19.

The clinical characteristics of the study participants are shown in Table 1 . The mean age of the study participants were $67.4( \pm 11.3)$ years, and $62.1 \%(n=126 / 203)$ of them were men. Increased stress levels, decreased exercise levels, increased total diet, snack, and prepared food intake were observed in approximately $40 \%,>50 \%$, and $20 \%$ of the participants during the COVID- 19 pandemic, respectively.

The results of correlations of the change in stress and lifestyle factors during the COVID-19 pandemic are shown in Table 2. There was a negative correlation between stress and exercise levels and a positive correlation between stress and prepared food intake. In addition, there was a negative correlation between exercise levels and snack or prepared food intakes. Furthermore, there was a correlation among diet intakes.

Furthermore, we investigated the association between the changes in the stress or lifestyle factors and changes in metabolic parameters. Among 183 participants, 24 participants' body weight data and 7 participants' HbA1c data were not recorded. Overall, there was a slight increase in body weight $(n=159)$ from $65.6( \pm 15.3) \mathrm{kg}$ to $65.8( \pm 15.2) \mathrm{kg}(p=0.126$, by paired $t$ test $)$ and the HbA1c level $(n=176)$ from $7.5( \pm 1.0) \%$ to $7.6( \pm 1.1) \%$ $(57.9( \pm 10.6) \mathrm{mmol} / \mathrm{mol}$ to $59.7( \pm 12.0) \mathrm{mmol} / \mathrm{mol})(p=$ 0.001 , by paired $t$ test) after 3 months. The results of the assessment of the association between the changes in the stress or lifestyle factors and change in metabolic parameters are shown in Table 3. Decreased exercise levels and increased total diet or snack intake were associated with increased body weight. Furthermore, increased total diet intake was associated with increased HbA1c levels.

Fig. 2 and Fig. 3 show the differences in body weight or HbA1c level changes between the groups. The change in body weight was significantly greater in patients who reported decreased exercise levels $(0.60[ \pm 2.11]$ vs. -0.16 $[ \pm 1.72] ; p<0.001)$, increased of total diet intake $(0.80$ $[ \pm 2.06]$ vs. $0.13[ \pm 1.93] ; p=0.010)$, and increasing of snack consumption $(0.70[ \pm 1.76]$ vs. $0.13[ \pm 2.00] ; p=$ $0.017)$ and tended to be greater in those who reported increased stress levels $(0.46[ \pm 2.19]$ vs. $0.06[ \pm 1.76] ; p=$ $0.281)$, and shortened sleep time $(0.74[ \pm 2.01] v s .0 .11$ $[ \pm 1.67] ; p=0.059)$ compared to those who did not. The change in HbAlc level was significantly greater in patients who reported shortened sleep time $(0.34[ \pm 0.52]$ vs. $0.13[ \pm 0.70] ; p=0.034)$ and increased total diet intake $(0.38[ \pm 0.88]$ vs. $0.11[ \pm 0.61] ; p=0.038)$ and tended to be greater in those who reported increased snack consumption $(0.38[ \pm 0.88]$ vs. $0.11[ \pm 0.61] ; p=$ 0.077) compared to those who did not. Moreover, we investigated the differences of lifestyle factors between the patients with weight gain or not, or worse glycemic control or not (Table 4). Patients with weight gain were associated with decreased exercise, increased total diet or increased snack consumption.

The results of the sub-analysis are shown in Table 5 . The relationship between decreased exercise levels and change in body weight or HbAlc significant for only in 


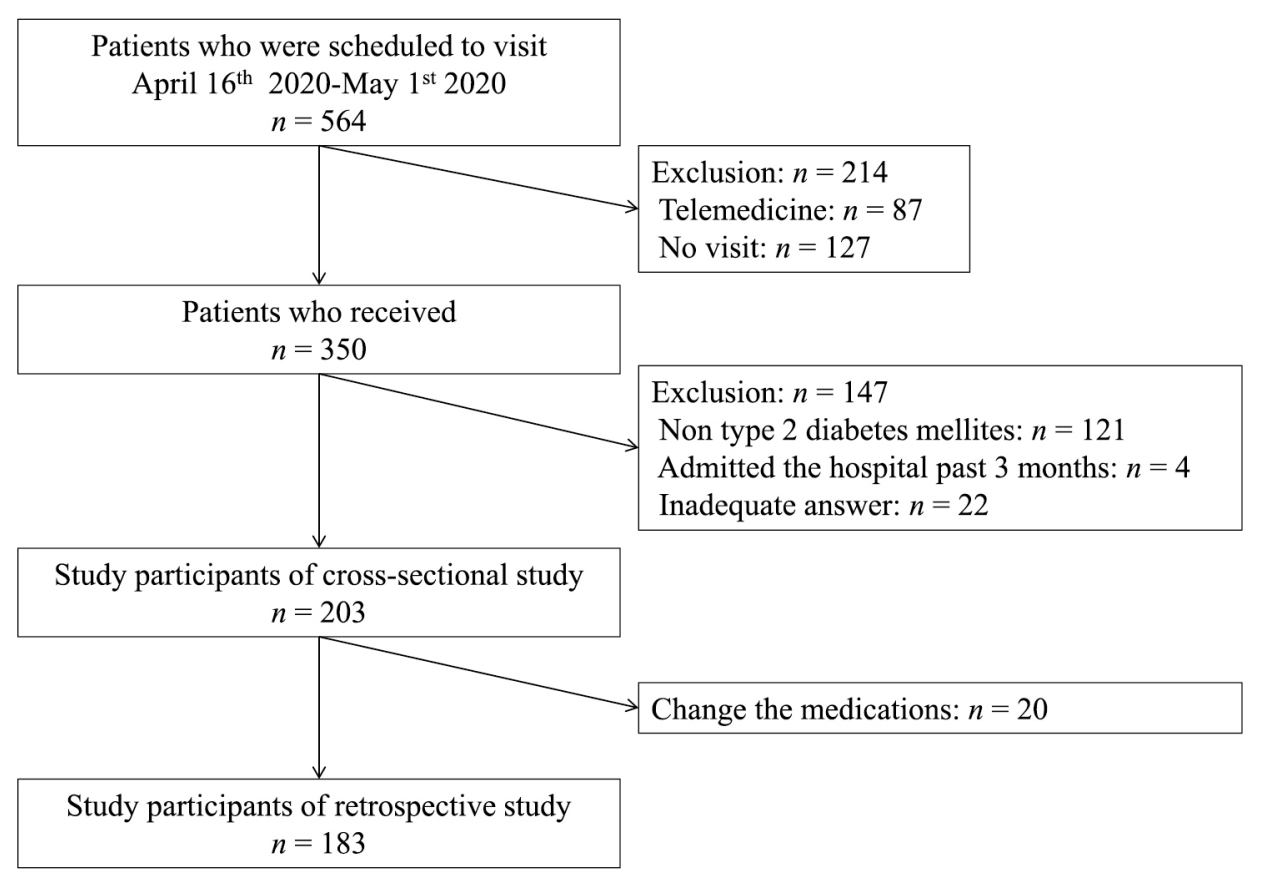

Fig. 1 Inclusion and exclusion flow

Table 2 The correlations of the change of stress and lifestyles factors

\begin{tabular}{|c|c|c|c|c|c|c|}
\hline & Stress & Sleep time & Exercise & $\begin{array}{l}\text { Total diet } \\
\text { intake }\end{array}$ & $\begin{array}{c}\text { Snack } \\
\text { consumption }\end{array}$ & $\begin{array}{l}\text { Prepared } \\
\text { food intake }\end{array}$ \\
\hline Stress & - & - & - & - & - & - \\
\hline Sleep time & $\begin{array}{c}r=-0.098 \\
p=0.187\end{array}$ & - & - & - & - & - \\
\hline Exercise & $\begin{array}{c}r=-0.285 \\
p<0.001\end{array}$ & $\begin{array}{l}r=0.156 \\
p=0.035\end{array}$ & - & - & - & - \\
\hline Total diet intake & $\begin{array}{l}r=0.115 \\
p=0.120\end{array}$ & $\begin{array}{l}r=0.054 \\
p=0.468\end{array}$ & $\begin{aligned} r & =0.052 \\
p & =0.483\end{aligned}$ & - & - & - \\
\hline Snack consumption & $\begin{array}{l}r=0.102 \\
p=0.170\end{array}$ & $\begin{array}{l}r=0.010 \\
p=0.896\end{array}$ & $\begin{array}{c}r=-0.161 \\
p=0.030\end{array}$ & $\begin{array}{l}r=0.315 \\
p<0.001\end{array}$ & - & - \\
\hline Prepared food intake & $\begin{array}{l}r=0.193 \\
p=0.009\end{array}$ & $\begin{array}{l}r=0.117 \\
p=0.114\end{array}$ & $\begin{array}{c}r=-0.087 \\
p=0.241\end{array}$ & $\begin{array}{l}r=0.206 \\
p=0.005\end{array}$ & $\begin{array}{l}r=0.219 \\
p=0.003\end{array}$ & - \\
\hline
\end{tabular}

Spearman rank correlation was performed to investigate the correlations. All items were evaluated by used visual analog scale. $0=$ considerably reduced, $5=$ no change, $10=$ considerably increased.

Table 3 The relationship between the change of stress or lifestyles factors and the change of metabolic parameters

\begin{tabular}{lcccccc}
\hline & Stress & Sleep time & Exercise & $\begin{array}{c}\text { Total diet } \\
\text { intake }\end{array}$ & $\begin{array}{c}\text { Snack } \\
\text { consumption }\end{array}$ & $\begin{array}{c}\text { Prepared } \\
\text { food intake }\end{array}$ \\
\hline Change of body weight $(n=159)$ & $r=0.02$ & $r=-0.02$ & $r=-0.33$ & $r=0.19$ & $r=0.24$ & $r=0.06$ \\
& $p=0.767$ & $p=0.770$ & $p<0.001$ & $p=0.016$ & $p=0.002$ & $p=0.449$ \\
Change of Hemoglobin A1c $(n=176)$ & $r=0.06$ & $r=-0.07$ & $r=-0.09$ & $r=0.16$ & $r=0.08$ & $r=0.03$ \\
& $p=0.445$ & $p=0.352$ & $p=0.241$ & $p=0.031$ & $p=0.284$ & $p=0.680$ \\
\hline
\end{tabular}

Spearman rank correlation was performed to investigate the correlations. All items of the change of stress and lifestyles factors were evaluated by visual analog scale. $0=$ considerably reduced, $5=$ no change, $10=$ considerably increased. 

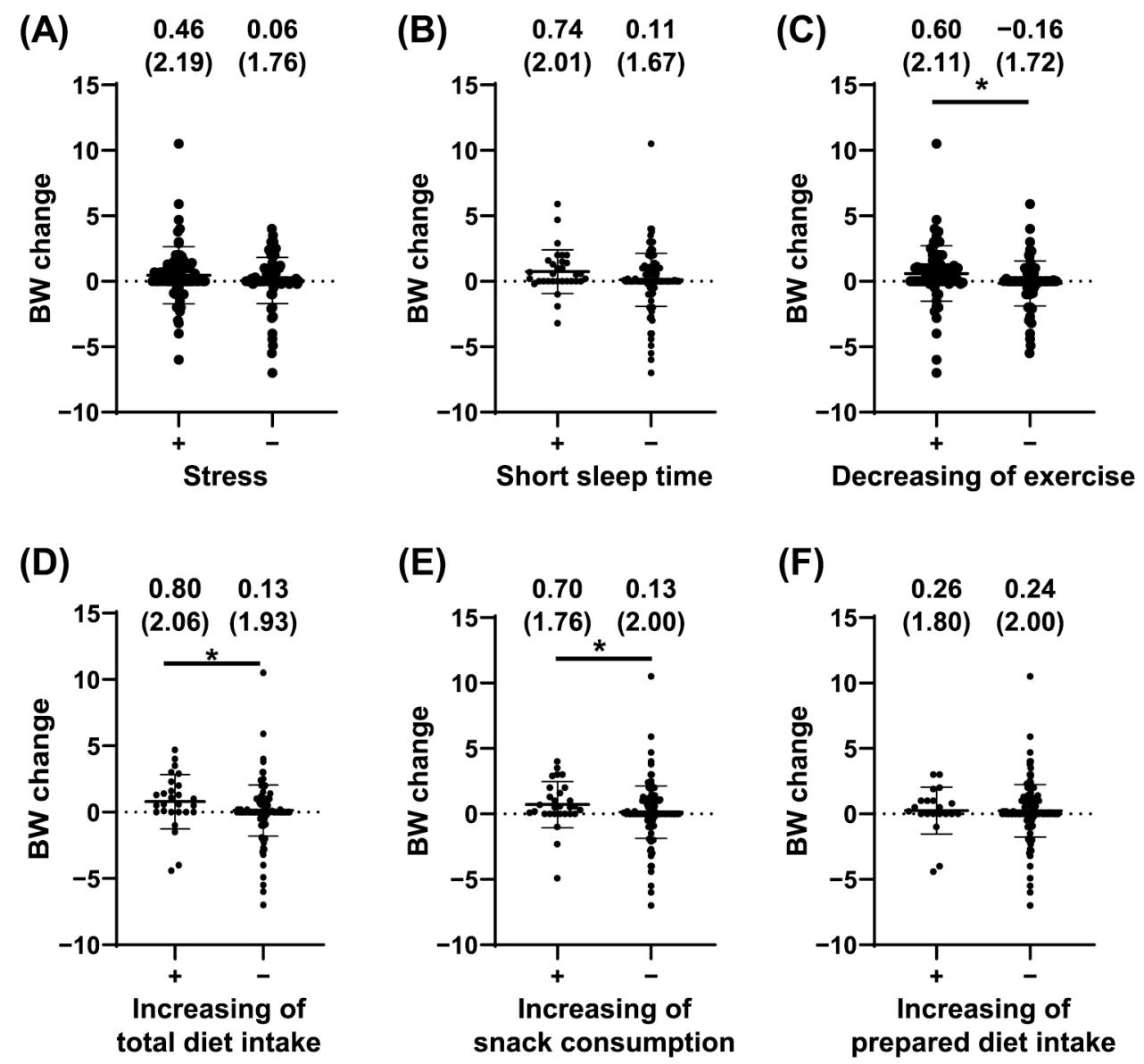

Fig. 2 The difference of the change of body weight between the groups

The difference between groups was evaluated by Student $t$-test. *; indicated $p<0.05$.

(A) Stress, feel high stress or not (visual analog scale [VAS] $\geq 6$ or not. (B) Sleep time, shorten sleep time or not (VAS $\leq 4$ or not). (C) Exercise, decreasing of exercise or not (VAS $\leq 4$ or not). (D) Total diet intake, increasing of total diet intake or not (VAS $\geq 6$ or not). (E) Snack intake, increasing of snack consumption or not (VAS $\geq 6$ or not). (F) Prepared food intake, increasing of prepared food intake or not (VAS $\geq 6$ or not).

men, whereas the relationship between increased snack consumption and change in body weight remained significant both in men and women. The relationship between decreased exercise levels or increased snack consumption and change in body weight remained significant for only patients aged $<65$ years. Furthermore, the relationship between the decreased exercise levels or increased snack or prepared food intake and changes in body weight or HbAlc levels remained significant for only patients who did not engage in regular exercise previously.

\section{Discussion}

In this study, we investigated the acute influence of the COVID-19 pandemic on the lifestyle of patients with type 2 diabetes mellitus. Based on our findings, patients with type 2 diabetes mellitus reported increased stress from the COVID-19 pandemic, which was associated with their exercise levels and diet intakes. Furthermore, these stress and lifestyle factors are associated with the changes in body weight and HbAlc.

Recent studies revealed that the COVID-19 pandemic is associated with increased stress in general populations $[8,9]$. External stress may lead to less physical activity and poor diet [18, 19]. In addition, stress is thought impact that metabolic parameters in patients with diabetes mellitus [20]. In previous studies, it has been reported that disasters, including earthquakes, floods, and hurricanes, were associated with increased stress and worse glycemic control in patients with type 2 diabetes mellitus [10, 21-27]. Although the association between stress and glycemic control was not observed in this study, unlike these previous disasters, the COVID-19 pandemic is ongoing and there are concerns that the impact on patients with diabetes mellitus will continue or become more severe. High glucose levels were associated with increased mortality in patients with SARS-CoV [28, 29] 

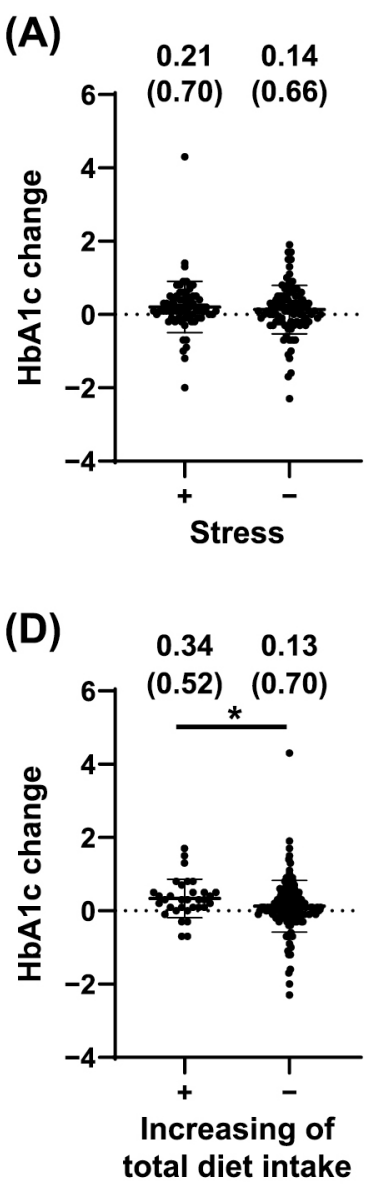
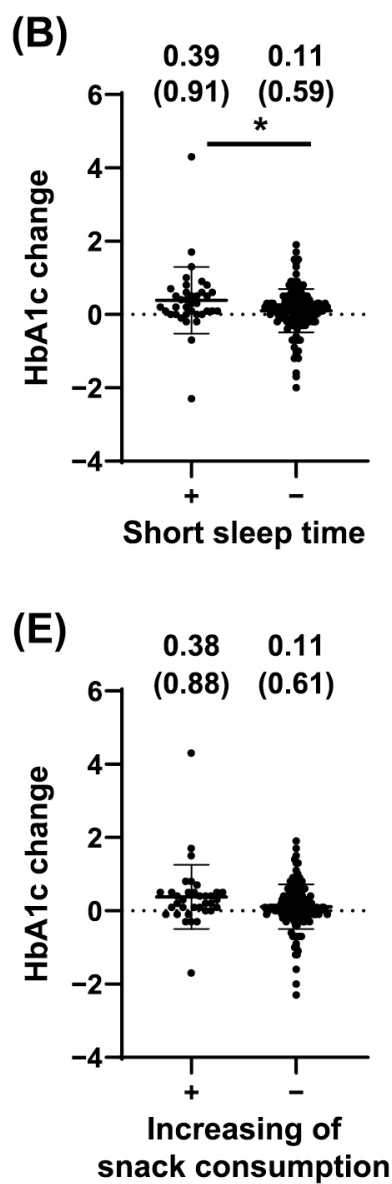
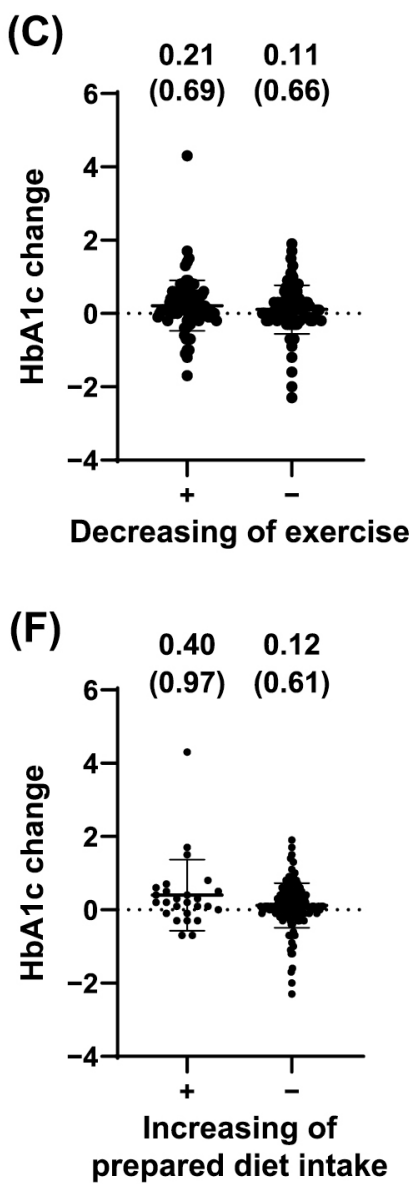

Fig. 3 The difference of the change of hemoglobin A1c between the groups

The difference between groups was evaluated by Student $t$-test. *; indicated $p<0.05$.

(A) Stress, feel high stress or not (visual analog scale [VAS] $\geq 6$ or not. (B) Sleep time, shorten sleep time or not (VAS $\leq 4$ or not). (C) Exercise, decreasing of exercise or not (VAS $\leq 4$ or not). (D) Total diet intake, increasing of total diet intake or not (VAS $\geq 6$ or not). (E) Snack intake, increasing of snack consumption or not (VAS $\geq 6$ or not). (F) Prepared food intake, increasing of prepared food intake or not (VAS $\geq 6$ or not).

Table 4 Differences of lifestyle factors between the patients with weight gain or worse glycemic control or not

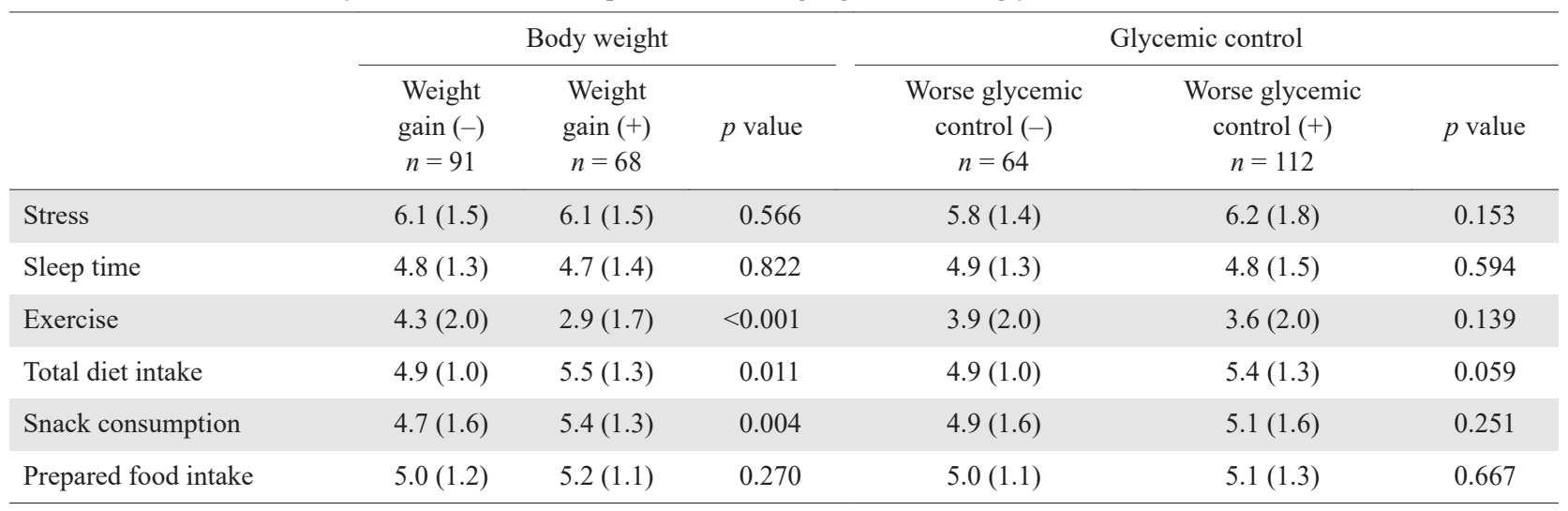

The differences in the lifestyle factors between the groups were evaluated using Mann-Whitney $U$ test. Data were shown as mean (SD).

and MERS-CoV [30]. Furthermore, high glucose levels are also reported to be associated with increased mortality in patients with COVID-19 [31]. Previous researchers have revealed that diet quality is associated with meta- bolic parameters, including glycemic control [32, 33], and that processed food intake is associated with calorie intake [34]. In addition, decreased exercise levels and increased snack consumption are associated with 
Table 5 Sub-analysis of the relationship between the change of stress or lifestyles factors and the change of metabolic parameters

\begin{tabular}{|c|c|c|c|c|c|}
\hline & & Exercise & Total diet intake & Snack consumption & Prepared food intake \\
\hline \multirow[t]{2}{*}{ Men } & Change of body weight, $n=104$ & $\begin{array}{l}r=-0.34 \\
p<0.001\end{array}$ & $\begin{array}{c}r=0.17 \\
p=0.091\end{array}$ & $\begin{array}{c}r=0.16 \\
p=0.113\end{array}$ & $\begin{array}{l}r=-0.03 \\
p=0.790\end{array}$ \\
\hline & Change of HbA1c, $n=110$ & $\begin{aligned} r & =-0.14 \\
p & =0.134\end{aligned}$ & $\begin{array}{c}r=0.24 \\
p=0.014\end{array}$ & $\begin{array}{c}r=0.07 \\
p=0.465\end{array}$ & $\begin{aligned} r & =0.16 \\
p & =0.105\end{aligned}$ \\
\hline \multirow[t]{2}{*}{ Women } & Change of body weight, $n=55$ & $\begin{array}{l}r=-0.30 \\
p=0.028\end{array}$ & $\begin{array}{l}r=0.25 \\
p=0.06\end{array}$ & $\begin{array}{c}r=0.38 \\
p=0.004\end{array}$ & $\begin{array}{c}r=0.18 \\
p=0.178\end{array}$ \\
\hline & Change of $\mathrm{HbA} 1 \mathrm{c}, n=66$ & $\begin{array}{l}r=-0.02 \\
p=0.987\end{array}$ & $\begin{array}{c}r=0.05 \\
p=0.714\end{array}$ & $\begin{array}{c}r=0.03 \\
p=0.784\end{array}$ & $\begin{array}{l}r=-0.11 \\
p=0.393\end{array}$ \\
\hline \multirow[t]{2}{*}{ Age under 65} & Change of body weight, $n=53$ & $\begin{array}{l}r=-0.44 \\
p=0.001\end{array}$ & $\begin{array}{c}r=0.06 \\
p=0.670\end{array}$ & $\begin{array}{c}r=0.29 \\
p=0.037\end{array}$ & $\begin{array}{l}r=-0.14 \\
p=0.323\end{array}$ \\
\hline & Change of $\mathrm{HbA} 1 \mathrm{c}, n=57$ & $\begin{array}{c}r=0.11 \\
p=0.432\end{array}$ & $\begin{aligned} r & =0.29 \\
p & =0.031\end{aligned}$ & $\begin{array}{l}r=-0.05 \\
p=0.712\end{array}$ & $\begin{array}{c}r=0.12 \\
p=0.366\end{array}$ \\
\hline \multirow[t]{2}{*}{ Age equal to and over 65} & Change of body weight, $n=106$ & $\begin{array}{l}r=-0.26 \\
p=0.008\end{array}$ & $\begin{array}{c}r=0.26 \\
p=0.007\end{array}$ & $\begin{array}{c}r=0.20 \\
p=0.042\end{array}$ & $\begin{array}{c}r=0.20 \\
p=0.037\end{array}$ \\
\hline & Change of HbA1c, $n=119$ & $\begin{array}{l}r=-0.19 \\
p=0.040\end{array}$ & $\begin{array}{c}r=0.09 \\
p=0.316\end{array}$ & $\begin{aligned} r & =0.15 \\
p & =0.096\end{aligned}$ & $\begin{array}{l}r=-0.02 \\
p=0.811\end{array}$ \\
\hline \multirow[t]{2}{*}{ Exercise habit (-) } & Change of body weight, $n=104$ & $\begin{array}{l}r=-0.37 \\
p<0.001\end{array}$ & $\begin{array}{c}r=0.17 \\
p=0.082\end{array}$ & $\begin{array}{c}r=0.35 \\
p<0.001\end{array}$ & $\begin{array}{c}r=0.08 \\
p=0.424\end{array}$ \\
\hline & Change of HbA1c, $n=116$ & $\begin{array}{l}r=-0.09 \\
p=0.318\end{array}$ & $\begin{array}{c}r=0.08 \\
p=0.376\end{array}$ & $\begin{array}{c}r=0.16 \\
p=0.078\end{array}$ & $\begin{array}{c}r=0.02 \\
p=0.867\end{array}$ \\
\hline \multirow[t]{2}{*}{ Exercise habit $(+)$} & Change of body weight, $n=55$ & $\begin{array}{l}r=-0.22 \\
p=0.108\end{array}$ & $\begin{array}{c}r=0.23 \\
p=0.085\end{array}$ & $\begin{array}{c}r=0.02 \\
p=0.895\end{array}$ & $\begin{array}{c}r=0.01 \\
p=0.942\end{array}$ \\
\hline & Change of HbA1c, $n=60$ & $\begin{aligned} r & =-0.08 \\
p & =0.535\end{aligned}$ & $\begin{array}{c}r=0.32 \\
p=0.013\end{array}$ & $\begin{array}{l}r=-0.08 \\
p=0.568\end{array}$ & $\begin{array}{c}r=0.08 \\
p=0.544\end{array}$ \\
\hline
\end{tabular}

Spearman rank correlation was performed to investigate the correlations. All items of the change of stress and lifestyles factors were evaluated by visual analog scale. $0=$ considerably reduced, $5=$ no change, $10=$ considerably increased.

increased body weight. Increasing body weight is a risk factor for poor glycemic control [35]. In the sub-analysis, the association between decreased exercise levels and changes in body weight was significant for age under 65 and those who did not exercise regularly. These patients have currently decreased their physical activity levels. In addition, the association between increased snack consumption and changes in body weight was significant. This result revealed that consumed snacks is one of the important treating targets of not increase body weight during pandemic. Therefore, we should focus on exercise of patients who are $<65$ years or without a regular exercise habit and diet, especially snack.

On the other hand, it is possible that the spread of COVID-19 infection has caused patients with diabetes to rethink their lifestyles. Thus, there is a possibility that the glycemic control and body weight would be better in the long term follow up. Moreover, there is a possibility that the results vary greatly depending on the timing of the survey. The survey was conducted in mid-April to early May, when we are most concerned about infection. Thus, further studies are needed for these associations. In addition, this study was performed in a single university medical center, thus there is a possibility that the background of patients in this study differs from that of the general Japanese population with diabetes, although average age and BMI are almost same as a previous study [36].

There are several limitations of this study. Firstly, the sample size was relatively small, and the participants were limited to a single center. In addition, this study only included the patients who visited our department. Therefore, the data of patients who did not visit were not included. There is a possibility that patients who did not visit our department experienced more stress or changes in lifestyle and, therefore, poor glycemic control. Secondly, the questionnaire of this study was simple and subjective and did not include quantitative evaluation. However, under the pandemic situation, the decreased contact time is essential to reduce the risk of disease transmission. Therefore, we only asked the patients simple and a minimal number of questions. Third, the causal relationship between the COVID-19 pandemic and the results of this survey is not wholly clarified. Because the 
questionnaire was collected only 1 time point for individual patients and answer for the question was based on the memory of the patients during the 3 months, answers could be strongly affected by the most recent feeling. Furthermore, there were no control in this study. Fourth, here is a possibility of change of answers if patients did not know their recent $\mathrm{HbAlc}$, because the questionnaire was performed by physician during medical examination. Lastly, this study included only Japanese patients; therefore, it is not clear whether our findings can be generalized to the populations of other countries.

In conclusion, many patients with type 2 diabetes mellitus reported increased stress levels and changes in lifestyle factors during the COVID-19 pandemic. These lifestyle changes were associated with changes in the body weight and HbA1c levels, even during the shortterm (i.e., 3 months). Given that the pandemic is ongoing, we should pay more attention to the management of stress and lifestyle factors in patients with type 2 diabetes mellitus to prevent the worsening of their glycemic control. Further research of exercise therapy or diet intervention without close contact with others is needed.

\section{Acknowledgments}

We would like to thank Editage (www.editage.com) for English language editing.

\section{Availability of Data and Materials}

The datasets used and/or analyzed during the current study are available from the corresponding author on reasonable request. We affirmed that the manuscript is an honest, accurate, and transparent account of the study being reported; that no important aspects of the study have been omitted; and that any discrepancies from the study as originally planned.

\section{Financial Disclosure}

None.

\section{Conflicts of Interest}

All authors have completed the ICMJE uniform disclosure. Dr. Hashimoto reports grants from Asahi Kasei Pharma and personal fees from Mitsubishi Tanabe Pharma Corp., Novo Nordisk Pharma Ltd., Sanofi K.K., and Daiichi Sankyo Co. Ltd. outside the submitted work. Dr. Osaka reports grants from Combi Corp., and personal fees from Eli Lilly Japan K.K, Sumitomo Dainippon Pharma Co., Ltd., MSD K.K., Novo Nordisk Pharma Ltd., Daiichi Sankyo Co. Ltd., Takeda Pharma Co. Ltd,
Nippon Boehringer Ingelheim Co. Ltd., Mitsubishi Tanabe Pharma Corp, Kyowa Kirin Co. Ltd., Kowa Pharma Co. Ltd., Ono Phama Co., Ltd., AstraZeneca plc., Toa Eiyo Corp., outside the submitted work. Dr. Ushigome received grant support from the Astellas Foundation for Research on Metabolic Disorders and the Japanese Study Group for Physiology and Management of Blood Pressure, donated fund Laboratory of Diabetes therapeutics is an endowment department, supported with an unrestricted grant from Ono Pharma. Co., Ltd., and received personal fees from MSD K.K., Daiichi Sankyo Co. Ltd., AstraZeneca plc, Kyowa Kirin Co. Ltd., Astellas Pharma Inc., Mitsubishi Tanabe Pharma Corp., Kowa Pharma Co. Ltd., Sumitomo Dainippon Pharma Co. Ltd., Novo Nordisk Pharma Ltd., Taisho Toyama Pharma Co., Ltd., Takeda Pharma Co., Ltd., and Nippon Boehringer Ingelheim Co. Ltd. outside the submitted work. Dr. Hamaguchi reports grants from Takeda Pharma Co. Ltd, Sanofi K.K., Mitsubishi Tanabe Pharma Corp., Asahi Kasei Pharma, Sumitomo Dainippon Pharma Co. Ltd., Kyowa Kirin Co. Ltd., Daiichi Sankyo Co. Ltd., Astellas Pharma Inc., Novo Nordisk Pharma Ltd., Nippon Boehringer Ingelheim Co. Ltd., and Eli Lilly Japan K.K., outside the submitted work. Dr. Yamazaki reports personal fees from MSD K.K., Takeda Pharma Co. Ltd, Daiichi Sankyo Co. Ltd., Kowa Pharma Co. Ltd., AstraZeneca plc., Kyowa Kirin Co. Ltd., Sumitomo Dainippon Pharma Co. Ltd., Kowa Pharma Co. Ltd., and Ono Phama Co., Ltd. outside the submitted work. Prof. Fukui received grants from Takeda Pharma Co. Ltd., Sanofi K.K., Kissei Phama Co. Ltd., Mitsubishi Tanabe Pharma Corp, Astellas Pharma Inc., Nippon Boehringer Ingelheim Co. Ltd., Daiichi Sankyo Co. Ltd., MSD K.K., Sanwa Kagagu Kenkyusho CO., LtD., Kowa Pharma Co. Ltd., Kyowa Kirin Co., Ltd., Sumitomo Dainippon Pharma Co., Ltd., Novo Nordisk Pharma Ltd., Ono Pharma Co. Ltd., Eli Lilly Japan K.K., Taisho Pharma Co., Ltd., Tejin Pharma LtD., Nippon Chemiphar Co., Ltd., Johnson \& Johnson k.k. Medical Co., Abbott japan Co. Ltd., and Terumo Corp., and received honoraria from Teijin Pharma Ltd., Arkray Inc., Kissei Pharma Co., Ltd., Novo Nordisk Pharma Ltd., Mitsubishi Tanabe Pharma Corp., Sanofi K.K., Takeda Pharma Co. Ltd., Astellas Pharma Inc., MSD K.K., Kyowa Kirin Co. Ltd., Sumitomo Dainippon Pharma Co. Ltd., Daiichi Sankyo Co. Ltd., Kowa Pharma Co. Ltd., Ono Pharma Co. Ltd., Sanwa Kagaku Kenkyusho Co. Ltd., Nippon Boehringer Ingelheim Co., Ltd., Taisho Pharma Co., Ltd., Bayer Yakuhin, Ltd., AstraZeneca K.K., Mochida Pharma Co. Ltd., Abbott japan Co. Ltd., Eli Lilly Japan K.K., Medtronic Japan Co. Ltd., and Nipro Corp. outside the submitted work. The other authors have nothing to disclose. 


\section{Contribution Statements}

C.M. and Y.Ho. obtained and analyzed data and wrote manuscript. These authors equally contributed to this work. Y.Ha. planned, and designed the work, obtained, analyzed and interpreted data and contributed to discussion. T.O. analyzed and interpreted data and contributed to discussion. F.T., R.K., H.N., S.M., T.S., N.N., E.U., M.H., and M.Y. obtained data and contributed to discus- sion. M.F. contributed to the conception of the work, obtained and interpreted data and contributed to discussion. All authors checked the final version, and agree to be responsibility for the work to ensure that any questions related to the accuracy or completeness of any of the work are appropriately investigated and resolved. Corresponding author, Yoshitaka Hashimoto, takes full responsibility for the work and publish the manuscript.

\section{References}

1. Cui J, Li F, Shi ZL (2019) Origin and evolution of pathogenic coronaviruses. Nat Rev Microbiol 17: 181-192.

2. Song Z, Xu Y, Bao L, Zhang L, Yu P, et al. (2019) From SARS to MERS, thrusting coronaviruses into the spotlight. Viruses 11: 59.

3. Drosten C, Günther S, Preiser W, van der Werf S, Brodt HR, et al. (2003) Identification of a novel coronavirus in patients with severe acute respiratory syndrome. $N$ Engl $J$ Med 348: 1967-1976.

4. Zaki AM, van Boheemen S, Bestebroer TM, Osterhaus AD, Fouchier RA (2012) Isolation of a novel coronavirus from a man with pneumonia in Saudi Arabia. $N$ Engl $J$ Med 367: 1814-1820.

5. Huang C, Wang Y, Li X, Ren L, Zhao J, et al. (2020) Clinical features of patients infected with 2019 novel coronavirus in Wuhan, China. Lancet 395: 497-506.

6. World Health Organization. Rolling updates on coronavirus disease (COVID-19) 2020 [31/03/2020]. Available from: https://www.who.int/emergencies/diseases/novelcoronavirus-2019/events-as-they-happen. Last access 1/May/2020

7. COVID-19 Map - Johns Hopkins Coronavirus Resource Center. Available from: https://coronavirus.jhu.edu/map. html Last access 1/May/2020

8. Bao Y, Sun Y, Meng S, Shi J, Lu L (2020) 2019-nCoV epidemic: address mental health care to empower society. Lancet 395: e37-e38.

9. Rajkumar RP (2020) COVID-19 and mental health: a review of the existing literature. Asian $J$ Psychiatr 52: 102066.

10. Inui A, Kitaoka H, Majima M, Takamiya S, Uemoto M, et al. (1998) Effect of the Kobe earthquake on stress and glycemic control in patients with diabetes mellitus. Arch Intern Med 158: 274-278.

11. Guan WJ, Ni ZY, Hu Y, Liang WH, Ou CQ, et al. (2020) Clinical characteristics of coronavirus disease 2019 in China. N Engl J Med 382: 1708-1720.

12. Onder G, Rezza G, Brusaferro S (2020) Case-fatality rate and characteristics of patients dying in relation to COVID-19 in Italy. JAMA 2020 in press. doi: 10.1001/ jama.2020.4683

13. Yang X, Yu Y, Xu J, Shu H, Xia J, et al. (2020) Clinical course and outcomes of critically ill patients with SARS-
CoV-2 pneumonia in Wuhan, China: a single-centered, retrospective, observational study. Lancet Respir Med 8: 475-481.

14. American Diabetes Association (2012) Diagnosis and classification of diabetes mellitus. Diabetes Care $35 \mathrm{Suppl}$ 1: S64-S71.

15. Haneda M, Utsunomiya K, Koya D, Babazono T, Moriya $\mathrm{T}$, et al. (2015) A new Classification of Diabetic Nephropathy 2014: a report from Joint Committee on Diabetic Nephropathy. J Diabetes Investig 6: 242-246.

16. Yasuda H, Sanada M, Kitada K, Terashima T, Kim H, et al. (2007) Rationale and usefulness of newly devised abbreviated diagnostic criteria and staging for diabetic polyneuropathy. Diabetes Res Clin Pract 77 Suppl 1: S178-S183.

17. Mineoka Y, Ishii M, Tsuji A, Komatsu Y, Katayama Y, et al. (2017) Relationship between limited joint mobility of the hand and diabetic foot risk in patients with type 2 diabetes. J Diabetes 9: 628-633.

18. Yau YH, Potenza MN (2013) Stress and eating behaviors. Minerva Endocrinol 38: 255-267.

19. Lin EH, Katon W, Von Korff M, Rutter C, Simon GE, et al. (2004) Relationship of depression and diabetes selfcare, medication adherence, and preventive care. Diabetes Care 27: 2154-2160.

20. Lloyd C, Smith J, Weinger K (2005) Stress and diabetes: a review of the links. Diabetes Spectrum 18: 121-127.

21. Allweiss P, Albright A (2011) Diabetes, disasters and decisions. Diabetes Management 1: 369-377.

22. Allweiss P (2019) Diabetes and disasters: recent studies and resources for preparedness. Curr Diab Rep 19: 131.

23. Kirizuka K, Nishizaki H, Kohriyama K, Nukata O, Arioka Y, et al. (1997) Influences of The Great Hanshin-Awaji Earthquake on glycemic control in diabetic patients. Diabetes Res Clin Pract 36: 193-196.

24. Fujihara K, Saito A, Heianza Y, Gibo H, Suzuki H, et al. (2012) Impact of psychological stress caused by the Great East Japan Earthquake on glycemic control in patients with diabetes. Exp Clin Endocrinol Diabetes 120: 560563.

25. Kondo T, Miyakawa N, Motoshima H, Hanatani S, Ishii $\mathrm{N}$, et al. (2019) Impacts of the 2016 Kumamoto Earthquake on glycemic control in patients with diabetes. $J$ 
Diabetes Investig 10: 521-530.

26. Ogawa S, Ishiki M, Nako K, Okamura M, Senda M, et al. (2012) Effects of the Great East Japan Earthquake and huge tsunami on glycaemic control and blood pressure in patients with diabetes mellitus. BMJ Open 2: e000830.

27. Ng J, Atkin SL, Rigby AS, Walton C, Kilpatrick ES (2011) The effect of extensive flooding in Hull on the glycaemic control of patients with diabetes. Diabet Med 28: 519-524.

28. Yang JK, Lin SS, Ji XJ, Guo LM (2010) Binding of SARS coronavirus to its receptor damages islets and causes acute diabetes. Acta Diabetol 47: 193-199.

29. Yang JK, Feng Y, Yuan MY, Yuan SY, Fu HJ, et al. (2006) Plasma glucose levels and diabetes are independent predictors for mortality and morbidity in patients with SARS. Diabet Med 23: 623-628.

30. Banik GR, Alqahtani AS, Booy R, Rashid H (2016) Risk factors for severity and mortality in patients with MERSCoV: analysis of publicly available data from Saudi Arabia. Virol Sin 31: 81-84.

31. Zhu L, She ZG, Cheng X, Qin JJ, Zhang XJ, et al. (2020) Association of blood glucose control and outcomes in patients with COVID-19 and pre-existing type 2 diabetes.
Cell Metab 31: 1068-1077.e3.

32. Hashimoto Y, Tanaka M, Miki A, Kobayashi Y, Wada S, et al. (2018) Intake of carbohydrate to fiber ratio is a useful marker for metabolic syndrome in patients with type 2 diabetes: a cross-sectional study. Ann Nutr Metab 72: 329-335.

33. Antonio JP, Sarmento RA, de Almeida JC (2019) Diet quality and glycemic control in patients with type 2 diabetes. J Acad Nutr Diet 119: 652-658.

34. Hall KD, Ayuketah A, Brychta R, Cai H, Cassimatis T, et al. (2019) Ultra-processed diets cause excess calorie intake and weight gain: an inpatient randomized controlled trial of ad libitum food intake. Cell Metab 30: 67-77.e3.

35. Look AHEAD Research Group (2014) Eight-year weight losses with an intensive lifestyle intervention: the look AHEAD study. Obesity (Silver Spring) 22: 5-13.

36. Yokoyama H, Oishi M, Takamura H, Yamasaki K, Shirabe SI, et al. (2016) Large-scale survey of rates of achieving targets for blood glucose, blood pressure, and lipids and prevalence of complications in type 2 diabetes (JDDM 40). BMJ Open Diabetes Res Care 4: e000294. 